Klas Jakub, Kluz Natalia, Makaryczew Mikołaj, Piwowar Klaudia. Treatment of schizophrenia and bipolar disorder (ChAD) - a review of the literature. Journal of Education, Health and Sport. 2021;11(9):473-483. eISSN 2391-8306. DOI http://dx.doi.org/10.12775/JEHS.2021.11.09.061

https://apcz.umk.pl/JEHS/article/view/JEHS.2021.11.09.061

https://zenodo.org/record/5524184

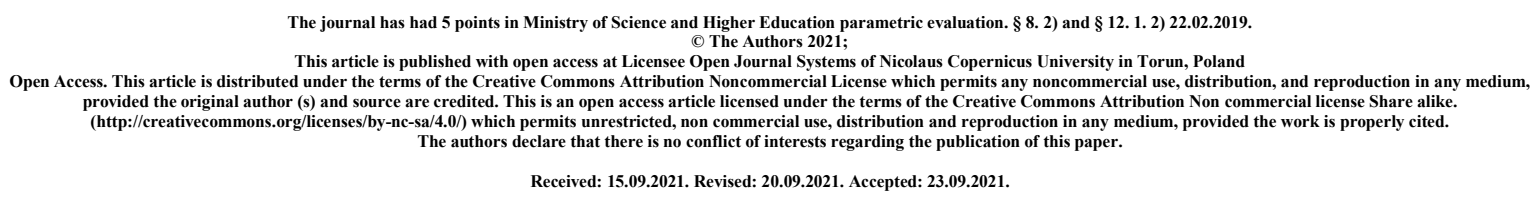

\title{
Treatment of schizophrenia and bipolar disorder (ChAD) - a review of the literature
}

\author{
Jakub Klas', Natalia Kluz ${ }^{1}$, Mikołaj Makaryczew ${ }^{1}$, Klaudia Piwowar ${ }^{1}$
}

${ }^{1}$ Medical University of Lublin

\section{ORCID ID and E-mail:}

Jakub Klas https://orcid.org/0000-0002-4795-1909 jakubklas99@gmail.com

Natalia Kluz https://orcid.org/0000-0002-5801-5913 nataliakluz99@gmail.com

Mikołaj Makaryczew https://orcid.org/0000-0003-4735-8221 mo7655010@gmail.com

Klaudia Piwowar https://orcid.org/0000-0001-8232-003X klaudiaklaudia66@gmail.com

\begin{abstract}
Introduction and aims of the study: The aim of this study is to present recent reports on the treatment and therapy of schizophrenia and bipolar disorder (ChAD). The current treatment of patients affected by these diseases is difficult and unsatisfactory, therefore it is necessary to find new therapeutic options that will improve the effectiveness of treatment
\end{abstract}

For the purpose of this study, scientific papers were reviewed using the Google Scholar search engine covering studies from 2016 to 2021. A dozen papers covering the scope of the publication were selected.

Results: In the treatment of schizophrenia, the use of cannabinoids is of greatest interest due to the action of the preparations on the endocannabinoid system. In the treatment of ChaD, 
promising reports have been published on the therapy with aripiprazole and the need to improve its use in the treatment of both akathisia and agitation. Furthermore, from the fact that abnormalities of calcium signalling are considered a possible pathophysiological process in $\mathrm{ChAD}$, it has been suggested that calcium channel $\mathrm{L}$ antagonists may be potential therapeutic agents in bipolar affective disorder. One study also demonstrated the potential use of vortioxetine in the treatment of patients with a depressive episode.

Conclusions: The results of recent studies on the treatment of schizophrenia and ChAD cited in this paper offer the prospect of creating treatment regimens that are more effective and targeted in the aforementioned diseases. However, further randomised trials are needed to confirm the effective use of the cited drugs in the treatment of these diseases.

\section{Key words: schizophrenia, ChAD, bipolar disorder}

\section{INTRODUCTION - characteristics of schizophrenia and bipolar disorder}

Schizophrenia is a serious mental illness. It is associated with impaired reasoning and a distorted perception of reality. It affects about $1 \%$ of the population and its causes are not well understood. There are many hypotheses about schizophrenia, mainly related to different neurotransmitter systems. It is treated as a neurodevelopmental disorder, which means that the patient may already be ill several years before the characteristic symptoms appear. Schizophrenia includes 3 groups of symptoms - positive, negative and cognitive. Positive symptoms are hallucinations and thought disorders, which are the core of the illness. Negative symptoms are for example flattening of affect and social withdrawal, while cognitive symptoms are for example learning and attention disorders. [1,2]

The course of the disease consists of acute seizures. After a few seizures, the patient's condition may improve and up to $1 / 3$ of patients will return to normal functioning. The remainder are at risk of recurrent episodes, which significantly reduce quality of life and cause a number of problems in everyday life. It is worth noting the data that life expectancy in patients with schizophrenia can be up to $20 \%$ shorter compared to the general population. In addition, these patients are at greater risk of suicide - about $4.9 \%$ commit suicide. As for the epidemiological data, they indicate an uneven distribution of the disease in society - most cases occur in lower socio-economic groups, and there is a greater risk of developing schizophrenia in men than in women over the life course. People aged 15-30 are most at risk 
of developing the illness. Risk factors for schizophrenia include: urban influences, migration, cannabis use, childhood trauma, infectious agents, obstetric complications and psychosocial factors. In addition, there are genetic factors that predispose to the development of schizophrenia. The heritability of schizophrenia can be as high as $80 \%$. If one parent has the disease, the probability that it will be passed on to offspring is $13 \%$. If it is present in both parents, the chance is greater than $20 \%$. If schizophrenia develops in one monozygotic twin, there is more than a $50 \%$ chance that the other twin will also. [2]

The diagnosis of schizophrenia is difficult and must be made after distinguishing between other psychiatric conditions as well as disorders such as heavy metal toxicity, adverse drug reactions and vitamin deficiencies that may manifest as psychosis. Making a diagnosis is facilitated by applying the DSM-V criteria for schizophrenia: A - symptoms, B - functioning, C - duration, D and F - exclusion criteria. Making a definitive diagnosis requires the recognition of a symptom complex for at least 6 months. [3]

For a first episode of schizophrenia, antipsychotic medication is recommended, with care to use the lowest effective therapeutic dose, and maintenance treatment for 18 months after the first episode. In the event of an acute exacerbation, the psychotropic dose should be increased or the medication changed to an effective one, and treatment should be continued for at least 4 weeks. For treatment-resistant schizophrenia (TRS), clozapine treatment should be initiated if resistance to two antipsychotics is present. In patients with clozapine-resistant schizophrenia, there are no clear guidelines for management as there is no effective treatment in this case - the patient remains a disabled person whom we are unable to help at the moment. If patients have symptoms of depression then antidepressants should also be used. [4]

An important point is that antipsychotics are not the ideal treatment for schizophrenia - they are only effective in about half of patients, relieve mainly positive symptoms, are associated with serious neurological and metabolic side effects and can lead to sexual dysfunction or agranulocytosis (clozapine). [1]

An additional and no less important aspect in the treatment of patients with schizophrenia is the use of psychotherapy, cognitive behavioural therapy, social skills training, and family support. Also, electroconvulsive therapy is used in patients with chronic schizophrenia. [3] Exercise can also be beneficial for patients with schizophrenia and offers the possibility of improving cognitive function, clinical symptoms and quality of life. [5]

Bipolar affective disorder (ChAD) is a chronic and potentially severe mood disorder [6]. It is characterised by disabling episodes of mania and depression. [7] Clinical and preclinical data 
indicate that treatment delay and/or exposure to a high number of mood episodes is associated with a worse clinical course. [8] [9].

Studies of twins have shown that bipolar affective disorder is one of the most heritable medical diseases. Polygenic heritability of the disorder has been demonstrated, and small loci located on genes have been found to contribute to bipolar affective disorder [7].

Despite the polygenic nature of the disorder, specific genes for bipolar affective disorder (DGKH, CACNA1C, ANK3) have been successfully identified in studies that used genomewide association analysis. [7]

The initial herald of ChAD is characterised by mood and energy disregulation. Due to the apparent low specificity of prodromal signs and symptoms of ChAD, it is currently neither possible nor advisable to predict the development of ChAD based solely on early phenomenology [11]. Diagnosing ChAD is also difficult in children, as manic episodes are common among children referred to psychiatry. The clinical picture of mania with onset in childhood is very severe and often co-occurs with other psychiatric disorders.[12]

Neurotic personality and negative extraversion predispose patients to depression, whereas neuroticism, extraversion and negative agreeableness predispose to manic episodes. [13]

Patient-reported depressive symptoms have been shown to be more frequent than manic symptoms and to cause greater disruption to occupational, family and social functioning. [14]

It is supposed that the clinical progression of the disease is subject to neurobiological changes, known as neuroprogression. This hypothesis is based on observations that changes in brain morphology, such as volume and grey matter reduction and ventricular enlargement, are more pronounced in chronic patients than in those with fewer episodes, supporting the need for early diagnosis and treatment initiation. [15] [16]

The treatment of bipolar affective disorder (ChAD) is difficult. One of the major challenges is the appropriate treatment of depression occurring in the course of ChAD. Too active treatment may lead to an unfavourable course of the disease - shortened remission, rapid phase change, drug-resistant depression. However, too conservative treatment may result in prolongation of depression duration and related problems - increased disability and risk of suicide. [17]

\section{OBJECTIVES AND METHODS}


The aim of this study is to present new therapeutic options in the treatment of schizophrenia and ChAD. A review of recent reports will be presented. In order to find the latest information, a review of scientific papers was performed using Google Scholar search engine covering articles from 2016 to 2021. A dozen scientific papers covering the scope of the publication were selected.

\section{REVIEW - modern therapies for the treatment of schizophrenia}

Non-adherence and resistance to pharmacotherapy often complicate the treatment of schizophrenia. The literature reports that approximately $20 \%$ of patients diagnosed with schizophrenia receive combination therapy and/or antipsychotic polytherapy.

There is a wide range of pharmacotherapy options; mainly based on serotonergic and dopaminergic antagonists/partial agonists, but the side effects and efficacy of antipsychotics with different pharmacological profiles leads experts to implement novel findings when it comes to pharmacotherapy and establishing reliable biomarkers of treatment. [18] [19]

Recently, a new concept has emerged in which philotherapy is used to treat schizophrenia. This method is based on herbal medicines, and the effect itself is due to the synergistic mechanisms of the compounds contained in a particular plant. The action of a particular herbal medicine is a kind of resultant of all the antagonisms and synergies between the components contained in it. [20]

Cannabidiol is a promising candidate in the treatment of schizophrenia discussed in this article. Increased function of the endocannabinoid system has been observed in patients with this disease entity. [18] [19]

It is responsible for the regulation of many vital functions, including learning, memory, mood, anxiety, drug dependence, eating behaviour, pain perception and cardiovascular function. It consists of cannabinoid receptors, secondary messengers, endogenous ligands and endocannabinoid degradation pathways. The system is still somewhat undiscovered, but so far three receptors have been described: cannabinoid type 1 (CB 1)-neuromodulation, stimulation of the central nervous system; cannabinoid type 2 (CB 2 )-anti-inflammatory and immunomodulatory effects and presynaptic inhibition; and G protein-coupled receptor 55 (GPR 55 ) [21] 
Studies have shown that cannabidiol reduces mesolimbic dopaminergic activity. [20] In turn, other experts claim that consumption of Cannabis sp. $z$ o.o. is associated with a higher likelihood of developing schizophrenia. However, the harmfulness of the drug depends on the THC and CBD content- THC promotes psychotic symptoms, while CBD exhibits antipsychotic effects. [22] [23]

CBD modulates the GABAergic system, where it acts directly on GABA A receptors. In addition, a determinant of successful therapy is the length of cannabis use - prolonged treatment disrupts neuronal synchrony in a similar manner to that seen in sufferers. Cannabis adversely potentiates positive symptoms, however, according to other sources, negative symptoms are reduced - CBD does not cause adverse catalepsy. It therefore acts like atypical antipsychotics. [22] [23]

Evidence regarding the safety and tolerability of cannabinoids for use in patients with schizophrenia is limited to preclinical as well as clinical studies. No significant side effects have been described that would disqualify this form of therapy. Drowsiness, diarrhoea and decreased appetite are among the most common side effects observed in clinical trials. [24]

However, further research is needed into the pathophysiology of the disease entity described, the associated genetic predisposition (based on GWAS), the modulatory mechanisms in impaired neurotransmission and other relevant factors to improve the clinical outcomes of this form of pharmacotherapy. [18] [19]

\section{REVIEW - modern therapies for the treatment of bipolar disorder}

The current state of knowledge allows for the development and implementation of effective pharmacotherapy for bipolar disorder. However, the effectiveness of this treatment is modest, and the number of side effects and potential toxicity of almost all drugs used leaves a wide field for new pharmacological solutions.

The current trend is to use atypical antipsychotics such as apripiprazole, olanzapine, and quetiapine. There is a sizable body of research supporting the validity and efficacy of such ideas. [25]

Aripiprazole is an atypical neuroleptic used in the treatment of bipolar I disorder. Analysis of the current use of this drug by Anna Z. Antosik - Wojcinska (2018) indicates that medicine using aripiprazole has not yet fully achieved a satisfactory clinical effect. [25] 
The author proves that a change of treatment from typical neuroleptics to aripiprazole in certain situations is completely justified. These include insufficient antipsychotic efficacy of another neuroleptic taken by the patient, poor tolerance to treatment with another neuroleptic, or intensification of negative symptoms. Moreover, after analysis of the drug's mechanism of action, the author suggests that other groups of patients (not only ChAD type I - according to the registration indications) may also benefit from treatment with aripiprazole, however, at present there are no clinical trials to confirm this. [25]

In addition, augmentation with aripiprazole and normotimine therapy often had superior or similar efficacy to augmentation with normotimine therapy and haloperidol in reducing symptoms as measured by the YMRS. In addition to decreasing the risk of extrapyramidal symptoms, weight gain and patient sedation were observed. [25] [27]

Similarly, when the effects of aripiprazole and lithium were compared. The risk of recurrence of a mixed episode or mania was comparably reduced, but the authors agree that patients receiving aripiprazole had fewer side effects. [25] [26]

The 2017 International Association for Neuropsychopharmacology guidelines position aripiprazole as monotherapy for first-line manic episodes. [25] It also benefits patients because of its safety and friendly side effect profile compared with first- and secondgeneration LPPs. Extrapyramidal symptoms and hyperprolactinemia are significantly less common. The most common are akathisia and nausea. This is the case in $1-10 \%$ of patients, and the intensity of complaints does not depend on the drug dose. [27] [28]

Finally, it turns out to be crucial to differentiate between aripiprazole side effects: akathisia and agitation, often confused with it. If agitation occurs, the drug dose should be reduced, in the case of akathisia - e.g. propanolol should be added. There is no justification for avoiding treatment of patients with the described agent. The full clinical potential of aripiprazole has not yet been exploited [25] [29]

Bipolar disorder is known to have a heritability of up to $80 \%$. Current genetic research is bringing us closer to developing more accurate and effective treatments. [30]

Abnormal calcium signaling is considered a possible pathophysiological process in ChAD. Therefore, genes encoding calcium channel proteins may play a significant role in not only psychiatric treatment but also in cardiology. Calcium channel antagonists used to treat hypertension may also play a role in the treatment of ChAD. [31][32]

One Japanese scientist, Yoshimizu, to learn about the expression and function of calcium channels, studied neurons induced from individuals genotyped for the major polymorphism of bipolar disorder. Neurons from homozygotes showed increased current flow compared to 
heterozygotes and homozygous non-risk subjects. This suggests that calcium channel L antagonists may be potential therapeutic agents for bipolar affective disorder. [33]

A 24-week study was conducted to evaluate vortioxetine therapy among patients with ChAD in a depressive episode. Each patient received vortioxetine in combination with currently used first- and second-generation normotimic medications. A total of 60 patients $(26$ men and 34 women) with ChAD were enrolled in the trial (23 patients with type I ChAD, 37 patients with type II ChAD). All patients were in outpatient treatment for a current depressive episode at the time of the experiment. [34]

Results indicated a significant improvement between when vortioxetine was included in treatment and each subsequent follow-up time point. The authors noted no relationship between response/remission rates as a result of vortioxetine therapy and vortioxetine dose, type of ChAD (I, II, or rapid phase change), clinical stage of ChAD (early vs. late), history of psychotic symptoms, depressive symptoms analyzed, or concomitantly used LN (quetiapine, lamotrigine, carbamazepine, aripiprazole, valproic acid or lithium salts). [34]

\section{CONCLUSIONS}

The results of recent studies on the treatment of schizophrenia and ChAD cited in this paper offer the prospect of creating treatment regimens that are more effective and targeted in the aforementioned diseases. However, further randomised trials are needed to confirm the effective use of the cited drugs in the treatment of these diseases.

\section{BIBLIOGRAPHY}

1. Stępnicki P, Kondej M, Kaczor AA. Current Concepts and Treatments of Schizophrenia. Molecules. 2018 Aug 20;23(8):2087. doi: 10.3390/molecules23082087. PMID: 30127324; PMCID: PMC6222385.

2. Janoutová J, Janácková P, Serý O, Zeman T, Ambroz P, Kovalová M, Varechová K, Hosák L, Jirík V, Janout V. Epidemiology and risk factors of schizophrenia. Neuro Endocrinol Lett. 2016;37(1):1-8. PMID: 26994378.

3. Ayano, Getinet. (2016). Schizophrenia: A Concise Overview of Etiology, Epidemiology Diagnosis and Management: Review of literatures. Journal of Schizophrenia Research. 3. 1-7. 
4. Remington G, Addington D, Honer W, Ismail Z, Raedler T, Teehan M. Guidelines for the Pharmacotherapy of Schizophrenia in Adults. Can J Psychiatry. 2017 Sep;62(9):604-616. doi: 10.1177/0706743717720448. Epub 2017 Jul 13. PMID: 28703015 ; PMCID: PMC5593252.

5. Girdler SJ, Confino JE, Woesner ME. Exercise as a Treatment for Schizophrenia: A Review. Psychopharmacol Bull. 2019 Feb 15;49(1):56-69. PMID: 30858639; PMCID: PMC6386427.

6. Rios AC, Noto MN, Rizzo LB, Mansur R, Martins FE Jr, Grassi-Oliveira R, Correll CU, Brietzke E. Early stages of bipolar disorder: characterization and strategies for early intervention. Braz J Psychiatry. 2015 Oct-Dec;37(4):343-9. doi: 10.1590/1516-4446-20141620. PMID: 26692432.

7. J.H. Barnett, J.W. Smoller, The genetics of bipolar disorder, Neuroscience, Volume 164, Issue $1, \quad 2009, \quad$ Pages 331-343, ISSN 0306-4522, https://doi.org/10.1016/j.neuroscience.2009.03.080.

8. Rybakowski JK. Genetic influences on response to mood stabilizers in bipolar disorder: current status of knowledge. CNS Drugs. 2013 Mar;27(3):165-73. doi: 10.1007/s40263-0130040-7. PMID: 23378337; PMCID: PMC3602611.

9. Reinares M, Colom F, Rosa AR, Bonnín CM, Franco C, Solé B, Kapczinski F, Vieta E. The impact of staging bipolar disorder on treatment outcome of family psychoeducation. $\mathrm{J}$ Affect Disord. 2010 Jun;123(1-3):81-6. doi: 10.1016/j.jad.2009.09.009. Epub 2009 Oct 23. PMID: 19853922.

10. Skjelstad DV, Malt UF, Holte A. Symptoms and signs of the initial prodrome of bipolar disorder: a systematic review. J Affect Disord. 2010 Oct;126(1-2):1-13. doi: 10.1016/j.jad.2009.10.003. Epub 2009 Nov 1. PMID: 19883943.

11. Wozniak J, Biederman J, Kiely K, Ablon JS, Faraone SV, Mundy E, Mennin D. Manialike symptoms suggestive of childhood-onset bipolar disorder in clinically referred children. J Am Acad Child Adolesc Psychiatry. 1995 Jul;34(7):867-76. doi: 10.1097/00004583199507000-00010. PMID: 7649957.

12. Quilty LC, Sellbom M, Tackett JL, Bagby RM. Personality trait predictors of bipolar disorder symptoms. Psychiatry Res. 2009 Sep 30;169(2):159-63. doi: 10.1016/j.psychres.2008.07.004. Epub 2009 Aug 21. PMID: 19699536.

13. Calabrese JR, Hirschfeld RM, Frye MA, Reed ML. Impact of depressive symptoms compared with manic symptoms in bipolar disorder: results of a U.S. community-based sample. J Clin Psychiatry. 2004 Nov;65(11):1499-504. doi: 10.4088/jcp.v65n1109. PMID: 15554762 . 
14. Berk M, Kapczinski F, Andreazza AC, Dean OM, Giorlando F, Maes M, Yücel M, Gama CS, Dodd S, Dean B, Magalhães PV, Amminger P, McGorry P, Malhi GS. Pathways underlying neuroprogression in bipolar disorder: focus on inflammation, oxidative stress and neurotrophic factors. Neurosci Biobehav Rev. 2011 Jan;35(3):804-17. doi: 10.1016/j.neubiorev.2010.10.001. Epub 2010 Oct 8. PMID: 20934453.

15. Fries GR, Pfaffenseller B, Stertz L, Paz AV, Dargél AA, Kunz M, Kapczinski F. Staging and neuroprogression in bipolar disorder. Curr Psychiatry Rep. 2012 Dec;14(6):667-75. doi: 10.1007/s11920-012-0319-2. PMID: 23090632.

16. Mansur RB, Cha DS, Asevedo E, McIntyre RS, Brietzke E. Selfish brain and neuroprogression in bipolar disorder. Prog Neuropsychopharmacol Biol Psychiatry. 2013 Jun 3;43:66-71. doi: 10.1016/j.pnpbp.2012.12.004. Epub 2012 Dec 20. PMID: 23266709.

17. Święcicki, Ł. (2014). Farmakoterapia depresji u pacjentów z chorobą afektywną dwubiegunową. Psychiatria, 11(2), 71-80.

18. Lupták M, Michaličková D, Fišar Z, Kitzlerová E, Hroudová J. Novel approaches in schizophrenia-from risk factors and hypotheses to novel drug targets. World J Psychiatry. 2021 Jul 19;11(7):277-296. doi: 10.5498/wjp.v11.i7.277. PMID: 34327122; PMCID: PMC8311514.

19. Stępnicki P, Kondej M, Koszła O, Żuk J, Kaczor AA. Multi-targeted drug design strategies for the treatment of schizophrenia. Expert Opin Drug Discov. 2021 Jan;16(1):101114. doi: 10.1080/17460441.2020.1816962. Epub 2020 Sep 11. PMID: 32915109.

20. Vitale RM, Iannotti FA, Amodeo P. The (Poly)Pharmacology of Cannabidiol in Neurological and Neuropsychiatric Disorders: Molecular Mechanisms and Targets. Int J Mol Sci. 2021 May 5;22(9):4876. doi: 10.3390/ijms22094876. PMID: 34062987; PMCID: PMC8124847.

21. Loss CM, Teodoro L, Rodrigues GD, Moreira LR, Peres FF, Zuardi AW, Crippa JA, Hallak JEC, Abílio VC. Is Cannabidiol During Neurodevelopment a Promising Therapy for Schizophrenia and Autism Spectrum Disorders? Front Pharmacol. 2021 Feb 4;11:635763. doi: 10.3389/fphar.2020.635763. PMID: 33613289; PMCID: PMC7890086.

22. Leweke FM, Rohleder C, Gerth CW, Hellmich M, Pukrop R, Koethe D. Cannabidiol and Amisulpride Improve Cognition in Acute Schizophrenia in an Explorative, Double-Blind, Active-Controlled, Randomized Clinical Trial. Front Pharmacol. 2021 Apr 29;12:614811. doi: 10.3389/fphar.2021.614811. PMID: 33995015; PMCID: PMC8117353.

23. Hoffman KL. From the Clinic to the Laboratory, and Back Again: Investigations on Cannabinoids and Endocannabinoid System Modulators for Treating Schizophrenia. Front 
Psychiatry. 2021 Jul 5;12:682611. doi: 10.3389/fpsyt.2021.682611. PMID: 34290632; PMCID: PMC8287066.

24. García-Gutiérrez MS, Navarrete F, Gasparyan A, Austrich-Olivares A, Sala F, Manzanares J. Cannabidiol: A Potential New Alternative for the Treatment of Anxiety, Depression, and Psychotic Disorders. Biomolecules. 2020 Nov 19;10(11):1575. doi: 10.3390/biom10111575. PMID: 33228239; PMCID: PMC7699613.

25. Antosik-Wójcińska, Anna Z. "Komu, kiedy iw jakiej dawce? Miejsce arypiprazolu w leczeniu schizofrenii i choroby afektywnej dwubiegunowej." Psychiatria i Psychologia Kliniczna 18.2 (2018)

26. SIWEK, Marcin; KRUPA, Anna Julia. Arypiprazol, olanzapina i kwetiapina w leczeniu schizofrenii i choroby afektywnej dwubiegunowej. Neuropsychiatria. Przegląd kliniczny, 2020, 12.3-4: 43-52

27. Marder SR, McQuade RD, Stock E et al.: Aripiprazole in the treatmentof schizophrenia: safety and tolerability in short-term, placebocontrolledtrials. Schizophr Res 2003; 61: 123136

28. Nowakowska, Karina, and Jakub Kaźmierski. "Arypiprazol-skuteczność i bezpieczeństwo terapii w codziennej praktyce." (2019).

29. Jarema M: Standardy leczenia farmakologicznego niektórych zaburzeń psychicznych. 2nd ed., Via Medica, Gdańsk 2015.

30. Harrison, Paul J., et al. "Innovative approaches to bipolar disorder and its treatment." Annals of the New York Academy of Sciences 1366.1 (2016): 76.

31. Levy, N.A. \& P.G. Janicak. 2000. Calcium channel antagonists for the treatment of bipolar disorder. Bipolar Disord.

32. Cipriani, A., K. Saunders, M.-J. Attenburrow, et al. 2016. Calcium channel antagonists in bipolar disorder. A systematic review of calcium channel antagonists in bipolar disorder and some considerations for their future development. Mol. Psychiatry. In press.

33. Yoshimizu, T., J.Q. Pan, A.E. Mungenast, et al. 2015. Functional implications of a psychiatric risk variant within CACNA1C in induced human neurons. Mol. Psychiatry

34. Dudek, Dominika, Anna Julia Krupa, and Janusz Kazimierz Rybakowski. "Dołączenie wortioksetyny $\mathrm{w}$ terapii depresji w chorobie afektywnej dwubiegunowej-24-tygodniowe, otwarte badanie naturalistyczne." 